\title{
Posterior servikal laminoforaminotomi
}

\author{
Posterior cervical laminoforaminotomy
}

\author{
H. Yener Erken
}

Wooridul Spine Hospital, Gangnam, Seul, S. Korea

\begin{abstract}
Posterior servikal laminoforaminotomi, foraminal disk herniyasyonu ve/veya osteofitlere bağlı servikal sinir kökü basılarının tedavisinde oldukça etkili bir yaklaşımdır. Posterior servikal omurgada minimal invaziv yöntemlerin kullanımı, anatominin daha basit olması nedeniyle, göreceli olarak diğer bölgelere göre daha kolaydır. Minimal invaziv cerrahi ile cilt insizyonu ve kas disseksiyonu minimal olmakta, böylelikle ameliyat sonrası boyun ağrısı ve kas spazmı daha az görülmektedir. Minimal invaziv laminoforaminotomi, güvenli bir teknik olup açık tekniğe göre sonuçları benzerdir. Minimal invaziv bir girişim olması nedeniyle, operasyonel morbidite azdır. Ancak, tekniği öğrenme süresinin uzun olması, cerrahi tecrübe gerektirmesi ve endoksopik ekipmanların maliyeti de akılda tutulmalıdır.
\end{abstract}

Anahtar sözcükler: posterior servikal laminoforaminotomi; minimal invaziv
Posterior cervical laminoforaminotomy is a very effective approach for the treatment of foraminal disc herniation and/or cervical nerve root compression due to osteophytes. The use of minimally invasive methods in the posterior cervical spine is relatively easy compared to other regions because of the simplicity of the anatomy. Minimally invasive surgery minimizes skin incision and muscle dissection, resulting in less postoperative neck pain and muscle spasms. Minimally invasive laminoforaminotomy is a safe technique and results are similar according to the open technique. Surgical morbidity is low because of the minimally invasive approach. However, the steep learning curve of the technique, the need of surgical experience, and the cost of endoscopic equipment should be kept in mind.

Key words: posterior cervical laminoforaminotomy; minimally invasive
P osterior servikal laminoforaminotomi foraminal disk herniyasyonu ve/veya osteofitlere bağlı servikal sinir kökü basılarının tedavisinde oldukça etkili bir yaklaşımdır. Illk olarak 1944'te Spurling ve Scoville ${ }^{[1]}$ tarafından tanımlanmış olup, halen posterolateral disk hernilerinin ve foraminal stenozun tedavisinde geçerli bir yöntem olarak kullanılmaktadır. Ayrıca, anterior yaklaşımların kontrendike olduğu ve yüksek riski olan hastalarda da alternatif bir yöntemdir. Servikal omurgada posterior yaklaşımlar, laminektomi, laminoplasti ve laminoforaminotomiyi içerir. Bu prosedürler, genellikle indirekt dekompresyona olanak sağlar. Bunun tek istisnası, direkt olarak çıkartılabilen foraminal disk hernileridir. ${ }^{[2]}$

Klasik açık posterior laminoforaminotomide, lamina ve lateral mass bileşkesine ve böylelikle foramene ulaşabilmek için geniş bir kesi yapmak gerekir. Paraspinal kaslardaki duyarlılıktan dolayı, bu kasların disseksiyonu ve retraksiyonu ameliyat sonrası belirgin bir boyun ağrısı ve spazma neden olabilmektedir. Bu nedenle, minimal invaziv teknikler posterior servikal omurga cerrahisinde günümüzde altın standart olarak kabul edilmektedir. Bu bölgede minimal invaziv yöntemlerin kullanımı, anatominin daha basit olması nedeniyle, göreceli olarak diğer bölgelere göre daha kolaydır. Minimal invaziv cerrahi, daha küçük cilt insizyonu ve daha az kas disseksiyonu gerektirmekte, böylelikle ameliyat sonrası boyun ağrısı ve kas spazmı daha az görülmektedir. ${ }^{[2]}$

Minimal invaziv omurga cerrahisinin gelişimindeki en önemli adım, tübüler retraktörler ile küçük çaplı ve yüksek çözünürlüklü endoskopların kullanılmaya başlanmasıdır. Bu cihazlar, derinde yer alan yapıların küçük kesilerden iyi kalitede görüntülenmesine olanak

- Illetişim adresi: Dr. H. Yener Erken, Wooridul Spine Hospital, Gangnam, Seul, S. Korea

Tel: 0535 - 8593472 e-posta: yenererken@yahoo.com

- Gelis tarihi: 5 Nisan $2017 \quad$ Kabul tarihi: 5 Nisan 2017 

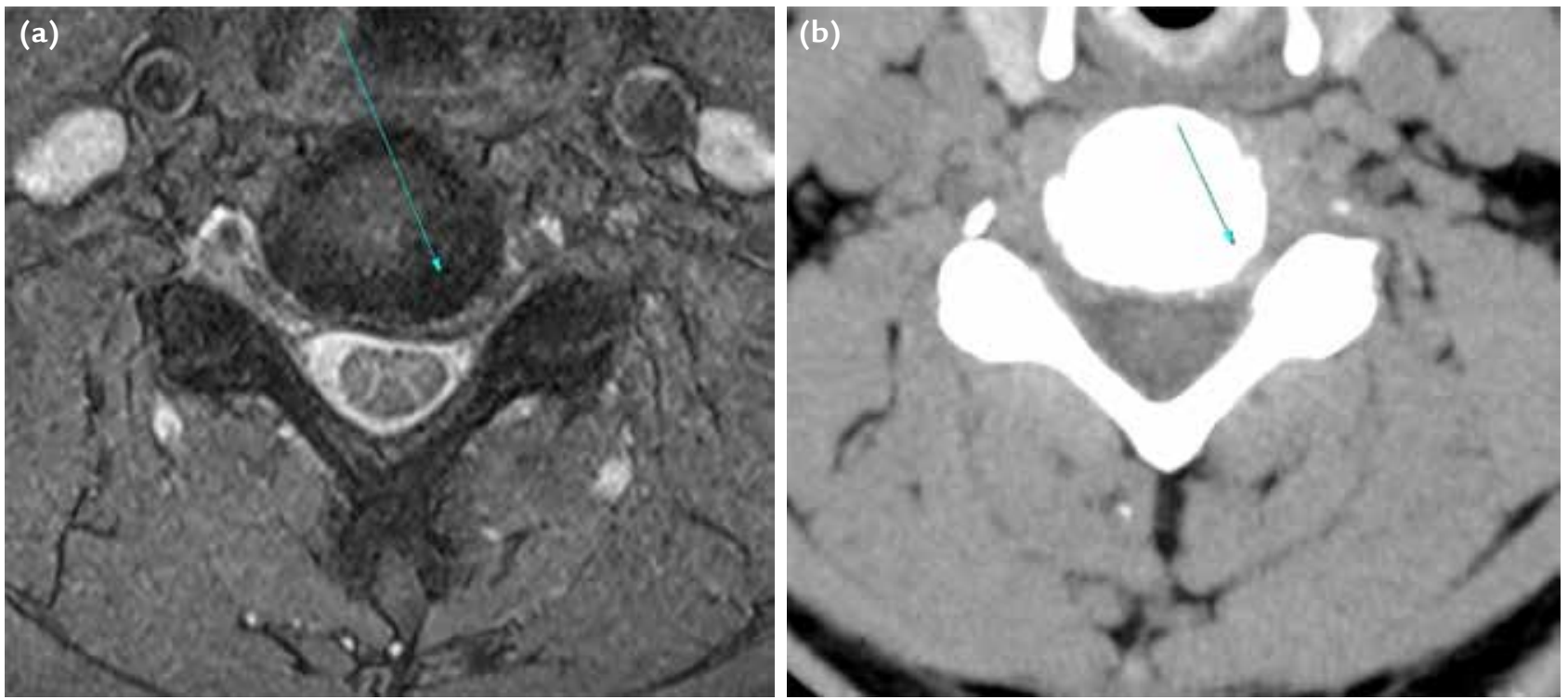

Şekil 1. a, b. Sol C5-C6 foraminal yumuşak disk herniyasyonunun $T 2$ aksiyel $M R$ ve $B T$ görüntüsü izlenmekte.

tanır. Böylelikle, hedeflenen bölgeye en az yumuşak doku hasarı ile ulaşılmış olur. Servikal omurgada da değişik sistemlerin kullanıma sunulmasıyla beraber, minimal invaziv posterior servikal omurga cerrahisi rutin olarak uygulanmaya başlanmıştır. Yumuşak doku dilatasyonuyla yerleştirilen tübüler veya diğer minimal invaziv retraktörlerin mikroskop altında kullanılmasıyla uygulanan mikroskopik laminoforaminotomi, tübüler retraktörlere monte edilen endoskopların kullanımıyla uygulanan mikroendoskopik laminoforaminotomi ve tamamiyle endoskop kullanılarak uygulanan tam endoskopik laminoforaminotomi, posterior servikal omurga cerrahisinde en sık uygulanan minimal invaziv cerrahi yöntemlerdir. Birbirlerine belirgin üstünlükleri olmayıp, hangi yöntemin seçileceği cerrahın seçimi ve tecrübesiyle ilgilidir. ${ }^{[2,3]}$

\section{ENDIKASYONLAR}

Minimal invaziv cerrahi sınırı bir alanda uyguladığı için, tek taraflı şikayeti olup tek veya iki seviyeli kök semptomları olan hastalar için en ideal yöntemdir. Servikal laminoforaminatomi ile yumuşak foraminal disk hernileri çıkartılabilmekte, aynı zamanda osteofit veya faset artropatisine bağlı foraminal stenozda dekompresyon sağlanabilmektedir. Hastanın şikayetleri, cerrahi öncesi görüntüleme çalışmaları ile birlikte değerlendirilmeli ve lateral kanal veya foramendeki sinir kökü basısı da konfirme edilmelidir. Hastada geniş bir herniyasyon olsa bile, rüptüre herninin apeksi spinal kordun (tekal kesenin değil) en lateral köşesinin daha lateralinde ise, bu hastalar laminoforaminotomi için aday olarak kabul edilirler. ${ }^{[4]}$

Genel olarak laminoforaminotomi uygulamasının diğer endikasyonları ise; santral kanal stenozu olmadan çok seviyeli foraminal stenoz varlığı, anterior diskektomi ve füzyon sonrası devam eden foraminal stenoz - sinir kökü basısı ve anterior yaklaşımların kontrendike olduğu durumlar olarak sayılabilir. Kontrendikasyonlar ise; trakeostomi varlığı, geçirilmiş servikal radyoterapi ve servikotorasik bileşkedeki disk hernileri (T1-T2)'dir. ${ }^{[2]}$

\section{PREOPERATIF DEĞERLENDIRME}

\section{Öykü}

Servikal radikülopati, çok tipik olan bir boyun ağrısı ve sinir kökü trasesinde kol ağrısı ile kendini gösterir. Ağrıyla beraber, sinir kökü trasesinde his değişiklikleri veya motor kayıp olabilir. Belirgin bir neden olmadan aniden semptomların ortaya çıkması, akut yumuşak foraminal disk hernisi için tipik bir bulgudur (Şekil 1). Aylar veya yıllar ile ifade edilen bir süredir devam eden kronik bulgular ise, spondilotik foraminal stenoz için tipiktir. Cerrahi uygulanmadan da şikayetler sıklıkla geçebildiği için, bu kararı vermeden önce anti-inflamatuvar tedavi, fizik tedavi, epidural enjeksiyonlar veya kök blokları gibi konservatif tedavi yöntemlerinin denenmesi gereklidir. Bu durumun tek istisnası, konservatif tedavi süreci devam ederken ciddi veya ilerleyici motor kaybı olan hastalardır. ${ }^{[4]}$ 


\section{Bulgu ve Semptomlar}

Çoğunlukla hastanın bulgu ve semptomları spesifik bir sinir kökünü işaret eder. Subjektif sensöriyel semptomlar, genellikle fizik muayenede elde edilen objektif bulgulardan daha fazla yol göstericidir. Örneğin; başparmağa yayılan yanıcı dizestezi C6 kök basısı için tipik bir subjektif bulgudur, ancak objektif bir bulgu olan hafif dokunma veya iğneleme testi sonuçları belirgin olmayabilir. Ağrı, genellikle spesifik bir sinir kökü ile uyumlu bir dermatomda ortaya çıkar.

\section{Fizik Muayene}

Fizik muayene, hastanın verdiği bilgiler doğrultusunda şüphelenilen bir kök basısını genellikle doğrular. Spesifik bir sinire bağlı motor, duyusal ve refleks bulgularının üçünün de aynı anda görülmesi tanıyı koymada oldukça yararlı olabilmesine rağmen, kalıcı bir duyu kaybı olmadan ortaya çıkan motor güçsüzlük ve refleks değişikliklerinin bir arada görülmesi daha sık bir bulgudur. Çok seviyeli spondilotik foraminal stenozu olan hastalarda yapılacak dikkatli bir fizik muayene, semptomatik olan sinir kökünü ortaya koymada en önemli basamaktır.

\section{Görüntüleme}

Manyetik rezonans (MR) servikal radikülopatinin tanısında en sık kullanılan görüntüleme yöntemidir. Spinal kanalın lateralinde veya foramenin mediyalinde izlenen bir sinir kökü basısı, laminoforaminotominin uygulanabilirliği açısından önemli bir bulgudur. MR çok kullanılan ve yararlı bir görüntüleme yöntemi olmasına rağmen, genellikle santral kanal stenozunu olduğundan daha ciddi gösterir ve foramenin aksiyel görüntülerini net olarak ortaya koymaz. Bu durumda, forameni daha iyi gösterebilen bir görüntüleme yöntemi olan intratekal kontrastlı veya kontrastsız bilgisayarlı tomografi (BT) yöntemi kullanılmalıdır. Cerrahiye karar vermeden önce, foraminal stenozun varlığı genellikle MR ve BT'nin beraber kullanılması ile ortaya konulur. İnstabilite şüphesinde ise fleksiyon ve ekstansiyon lateral servikal grafiler kullanılır. Ciddi spondilozu olan olgularda veya MR görüntüsü çok kötü olan aşırı kilolu hastalarda BT miyelografi de kullanılabilir.

\section{CERRAHI TEKNIK}

Cerrahide, yüzükoyun pozisyon ya da oturur pozisyon tercih edilebilir. Her iki pozisyonda da, hastanın kafası Mayfield-Kees sabitleyici ile sabitlenebilir. Biz klinik uygulamamızda, yüzükoyun pozisyonu tercih edip hastanın kafasını ameliyat masasına bantlarla sabitlemekteyiz. Yüzükoyun pozisyonda daha kaudal seviyelerde iyi floroskopik görüntü elde edebilmek için, masaya sabitlenen bantlar ile omuzlar da traksiyona alınır. Aynı zamanda sırt bölgesine de cildi traksiyona alacak bir bant yapıştırılarak, operasyon bölgelerindeki cilt katlantıları ortadan kaldırılır (Şekil 2). Floroskopi veya gezici röntgen ile lateral görüntü alınır ve seviye tespiti yapılır. Mikroskopik laminoforaminotomi yapılıyorsa, ilgili seviyede orta hattın $0,5 \mathrm{~cm}$ lateralinden hedeflenen foramen insizyonun tam ortasında olacak şekilde 2-2,5 cm'lik insizyon ardından, kaslar spinöz çıkıntı ve laminadan diseke edilir ve cerrahi alana ulaşılır. Eğer operasyon endoksopik yöntem ile gerçekleştiriliyorsa, lamino-faset bileşkesinin bulunması önemlidir. Floroskopide AP görüntülerde, çizilen düz çizgiler ile orta hat ve lateral mass'ın en lateral noktaları belirlenir. Lamino-faset bileşke de AP floroskopik görüntülerde çekilen bir düz çizgi ile işaretlenir. Sonrasında lateral floroskopik görüntüden yararlanarak, 18G spinal iğne ile daha önce AP görüntülerde belirlenmiş olan lamino-faset bileşke çizgisi üzerinden girilir, foramen seviyesi ve insizyon yeri belirlenir ve insizyon yapılır. Mikroendoskopik veya tam endoskopik yöntem tercih ediliyorsa, kullanılacak sistem ile uyumlu olarak 1-2 cm'lik insizyon yapılır. İnsizyon yapıldıktan sonra, dilatatörlerin yerleştirilmesi için fasya da kesilmelidir. Lateral floroskopik görüntüler altında, kılavuz tel veya obturator yerleştirilir. Biz kliniğimizde, kılavuz telin mediyal yerleşimine bağı dural yaralanma veya lateral yerleşimine bağlı vertebral arter yaralanması riskinden dolayı, kılavuz tel kullanmayıp obturatoru direkt yerleştirmekteyiz. Obturator yerleştirildiğinde, lamina üzerindeki bağ ve kaslar da obturator ile sıyrilır. Obturator üzerinden, seri yumuşak doku dilatatörler ve en son olarak kullanılacak sistem ile uyumlu olarak, 14-18 mm'lik tübüler retraktör veya 8-12 mm'lik endoskopik kanül yerleştirilir. Cerrahın tercihine göre, açılı ya da düz endoskopik kanül kullanılabilir. Anteroposterior (AP) floroskopik görüntü çekilerek, tübüler retraktör veya endoskopik kanülün lamino-faset bileşke üzerinde olduğundan emin olunur. Tübüler retraktör veya endoskopik kanül masaya sabitlenir. Aynı insizyon kullanılarak ve işlemler tekrarlanarak, bir üst ve/veya bir alt seviye de aynı seansta ameliyat edilebilir (Şekil 3). Mikro-endoskopik yöntem uygulanıyorsa, endoskop tübüler retraktöre monte edilir. Tam endoskopik yöntemde ise, endoskop kanülün içine yerleştirilir.

Superior lamina ve superior vertebranın fasetinin mediyal kenarı üzerindeki yumuşak dokular, bipolar koter kullanılarak temizlenir. Yüksek hızlı drill ile superior ve inferior vertebra laminalarına hemilaminotomi uygulanır. Superior vertebranın inferior fasetinin mediyal kenarı drill'endikten sonra, inferior vertebranın superior faseti ortaya konur ve mediyal sınırı drill'enir (Şekil 4). Sonrasında küret yardımı ile, ligamentum 


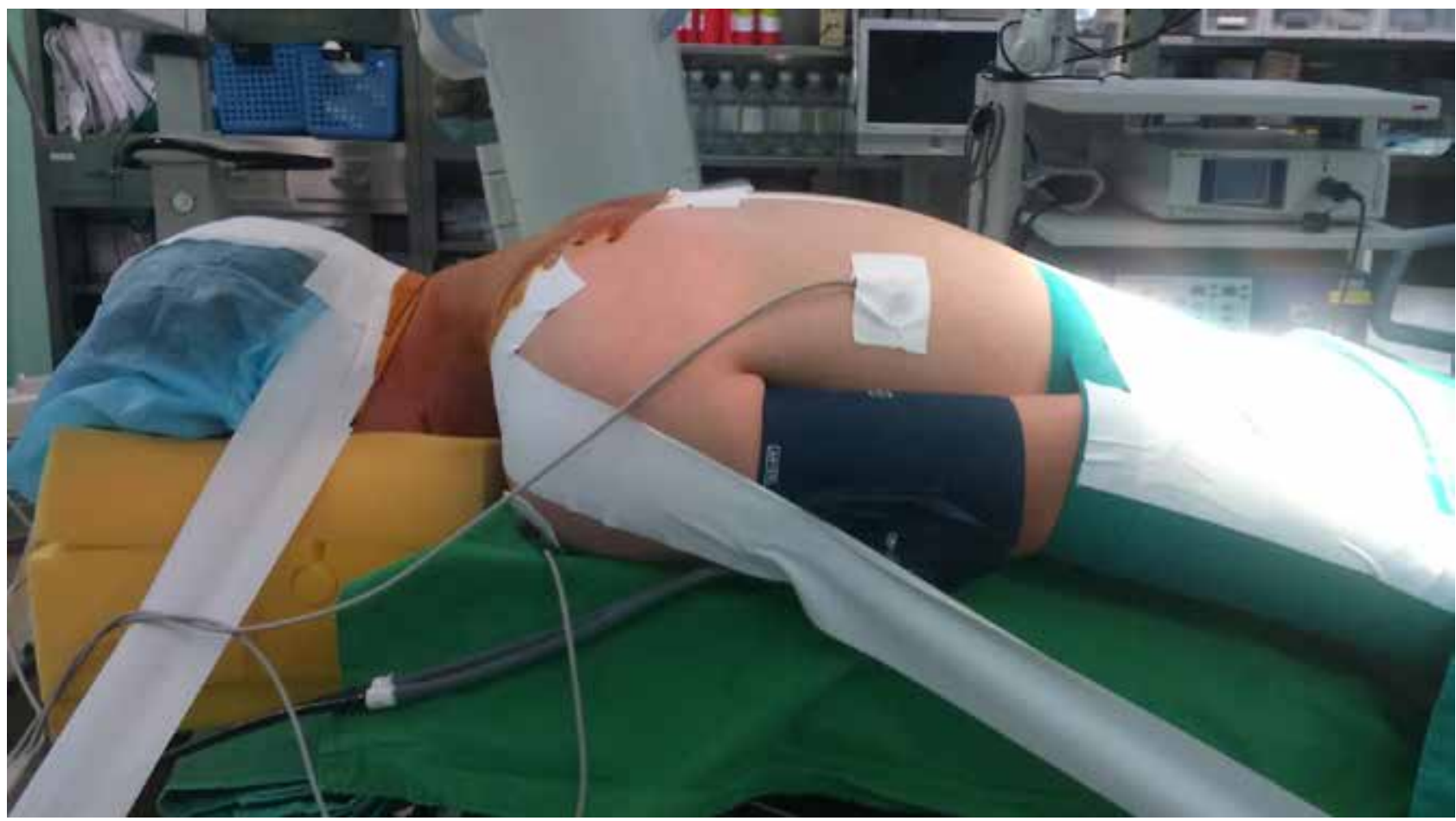

Şekil 2. Klinik uygulamamızda yüzükoyun pozisyonu tercih edip, hastanın kafasını ameliyat masasına bantlarla sabitlemekteyiz. Yüzükoyun pozisyonda kaudal seviyelerde daha iyi floroskopik görüntü elde edebilmek için, masaya sabitlenen bantlar ile omuzlar da traksiyona alınır.
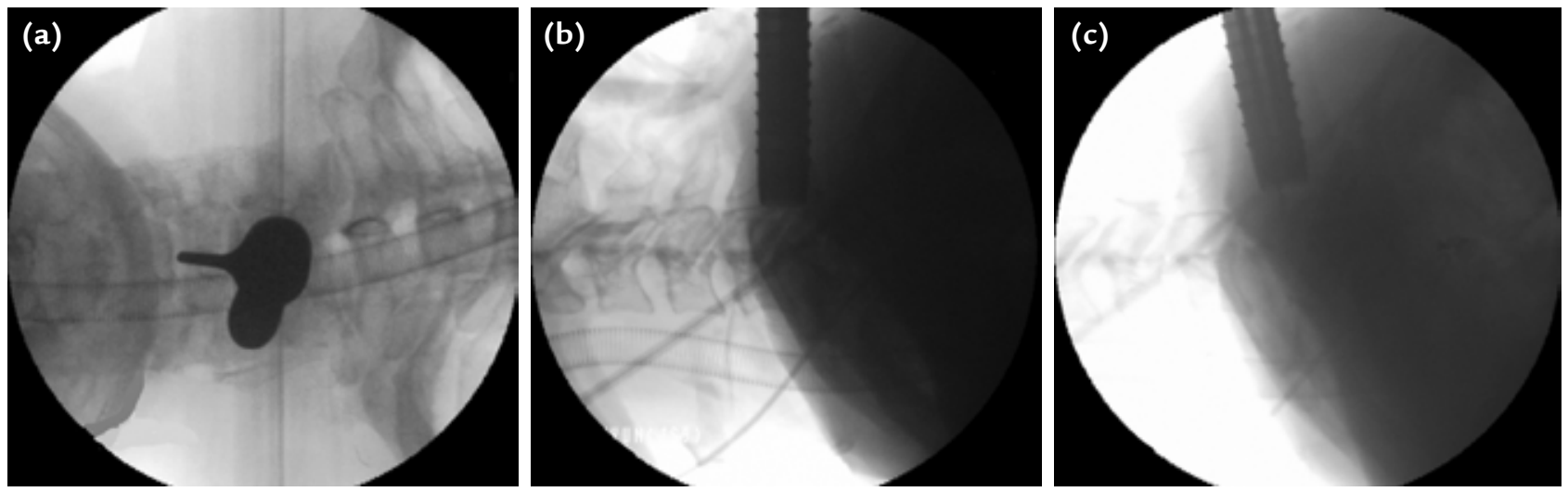

Şekil 3. a-c. Sol C5-C6 ve C6-C7 seviyelerine uygulanan iki seviyeli tam endoskopik laminoforaminotomi işleminde endoskopik kanülün yerleşiminin floroskopik görüntüsü. AP görüntüde endoskopik kanül lamino-faset bileşkesine yerleştirilmelidir (a). Endoskopik kanülün C5-C6 ve C6-C7 foramen seviyelerine aynı insizyondan yerleştirilmesi izlenmektedir (b, c).

flavum drill'enen bölgenin altından ayrılır ve "Kerrison Rongeur" kullanılarak hemilaminotomi ve kemik rezeksiyonu tamamlanır. Ligamentum flavum, dissektör yardımı ile duranın lateral sınırı ve sinir kökü üzerinden dikkatlice disseke edilip rezeke edilir. Sinir kökü üzerindeki epidural venöz pleksus, bipolar koter ile koterize edilir. Yeterli kemik rezeksiyonu ve ligamentum flavum disseksiyonu yapılması, manipülasyon esnasında dural yaralanma riskini azaltması nedeniyle önemlidir. “Kerrison Rongeur"ler kullanılarak foraminotomi tamamlanır (Şekil 5).

Penfield dissektörü ve sinir kökü mobilize edilir ve ek patolojilerin varlığı araştırılır. Sinir kökünün aksillasının disseksiyonu ile, genellikle disk herniyasyonu ve/veya Luschka eklemindeki osteofite ulaşılır. Disk herniyasyonu, Luschka ekleminin şekli ve açılanması 


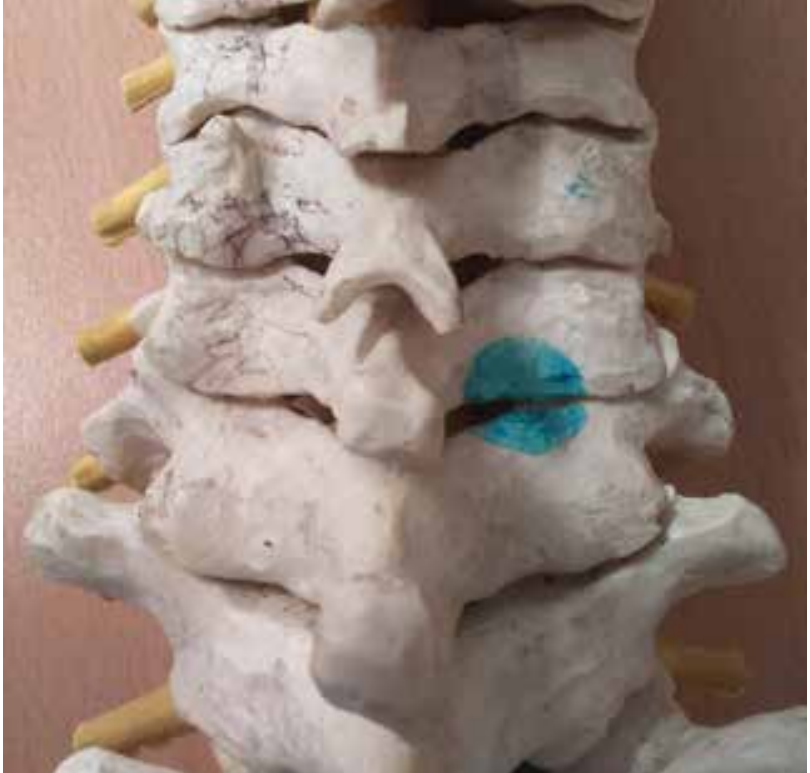

Şekil 4. Laminoforaminotominin sınırları omurga maketi üzerinde işaretlenmiştir.

nedeniyle, nadiren sinir kökünün omuzunda yer alır. Yumuşak disk herniyasyonu varsa, serbest parça çıkartılır. Disk aralığının eksplorasyonu gereksizdir. Bu bölgedeki osteofitik çıkıntılar rezeke edilemez; o yüzden mümkün olduğunca geniş laminoforaminotomi ile, sinir kökünün indirekt dekompresyonu sağlanmalı ve bundan emin olunmalıdır. Foraminotominin sınırları, cerrahi öncesi MR ve BT'de sinir kökü basısının sınırlarına göre planlanmalıdır. Cerrahi sırasında, superior ve inferior pediküllerin mediyal ve lateral sınırlarının sinir probu ile palpe edilerek foramen ve kanalın sınırlarının belirlenmesi ve sinirin foramen boyunca dekomprese olduğunun sinir probu veya Woodson dissektörü kullanılarak konfirme edilmesi ile, dekompresyonun yeterli olduğuna karar verilir. Böylelikle, gereksiz faset rezeksiyonunu önlenir. Hemostaz sağlandıktan sonra, kullanılan ekartör, tübüler retraktör veya endoskopik kanül çıkartılır. Fasya ve cilt sütüre edilir.

\section{POSTOPERATIF TAKIP}

Minimal invaziv posterior servikal laminoforaminotomi sonrası hastalar, genellikle operasyonun ertesi gününde sadece ağrı kesiciler gerektiğinde kullanmaları için reçete edilerek taburcu edilebilirler. Hastalar normal günlük yaşantılarına aşamalı olarak dönerler ve inmobilizasyon uygulanmasına gerek yoktur. Pasif ROM egzersizlerine mümkün olduğunca çabuk

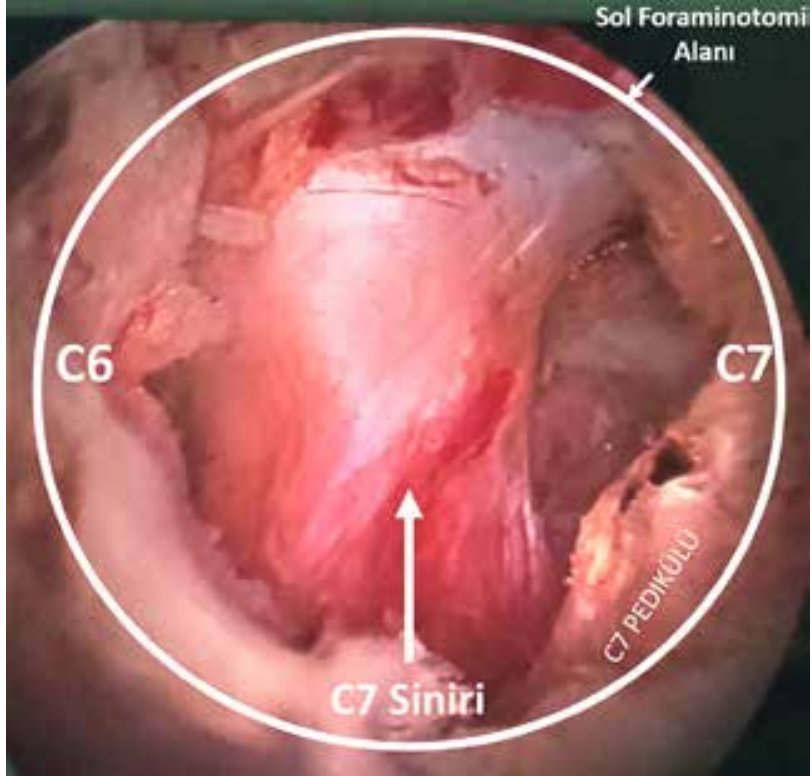

Şekil 5. Sol C6-C7 forameninde C7 kök basısı nedeniyle uygulanan tam endoskopik laminoforaminotominin tamamlanmış hali izlenmekte.

başlayan hastalar, operasyon sonrası 3.-5. günlerde kontrole çağrılır ve yaraları kontrol edilir. Bu aşamada hastaya, evde yapacağı boyun kuvvetlendirme ve mobilizasyon egzersizleri tarif edilmelidir. Ağrısı fazla olan nadir sayıdaki ve fiziksel güç gerektiren işlerde çalışan hastalarda ise, fizik tedavi programına başlanabilir. Genellikle hastalar dört hafta içinde tüm normal aktivitelerine dönebilir.

\section{KOMPLIKASYONLAR}

Literatürde bildirilmiş komplikasyonlar; nüks disk herniyasyonu, venöz kanamaya bağlı aşırı kanama ve operasyondaki pozisyona bağı kontralateral torasik çıkış sendromudur. ${ }^{[2]}$ Fessler ve Khoo ${ }^{[5]}$, operasyondaki kanamanın oturur pozisyonda yüzükoyun pozisyona göre belirgin olarak daha az olduğunu bildirmişlerdir. Aynı çalışmadaki 25 hastalık seride, üç hastada durotomi komplikasyonu bildirilmiştir. ${ }^{[2,5]}$ Adamson ${ }^{[2,6]}$ ise, 100 hastalık mikro-endoskopik laminoforaminotomi serisinde, iki hastada durotomi komplikasyonu bildirmiştir. Adamson bu hastalarda lomber dren yerleştirmemiş, Fessler ise operasyon sonrası 2-3 gün süre ile lomber dren yerleştirmiştir. ${ }^{[2,5,6]}$ Minimal invaziv yöntemler sonrası psödomeningosel, literatürde bildirilmemiş olup, semptomatik psödomeningosel oluşma riski, insizyon ve eksplorasyonun küçük olmasından dolayı düşüktür. ${ }^{[2]}$ 

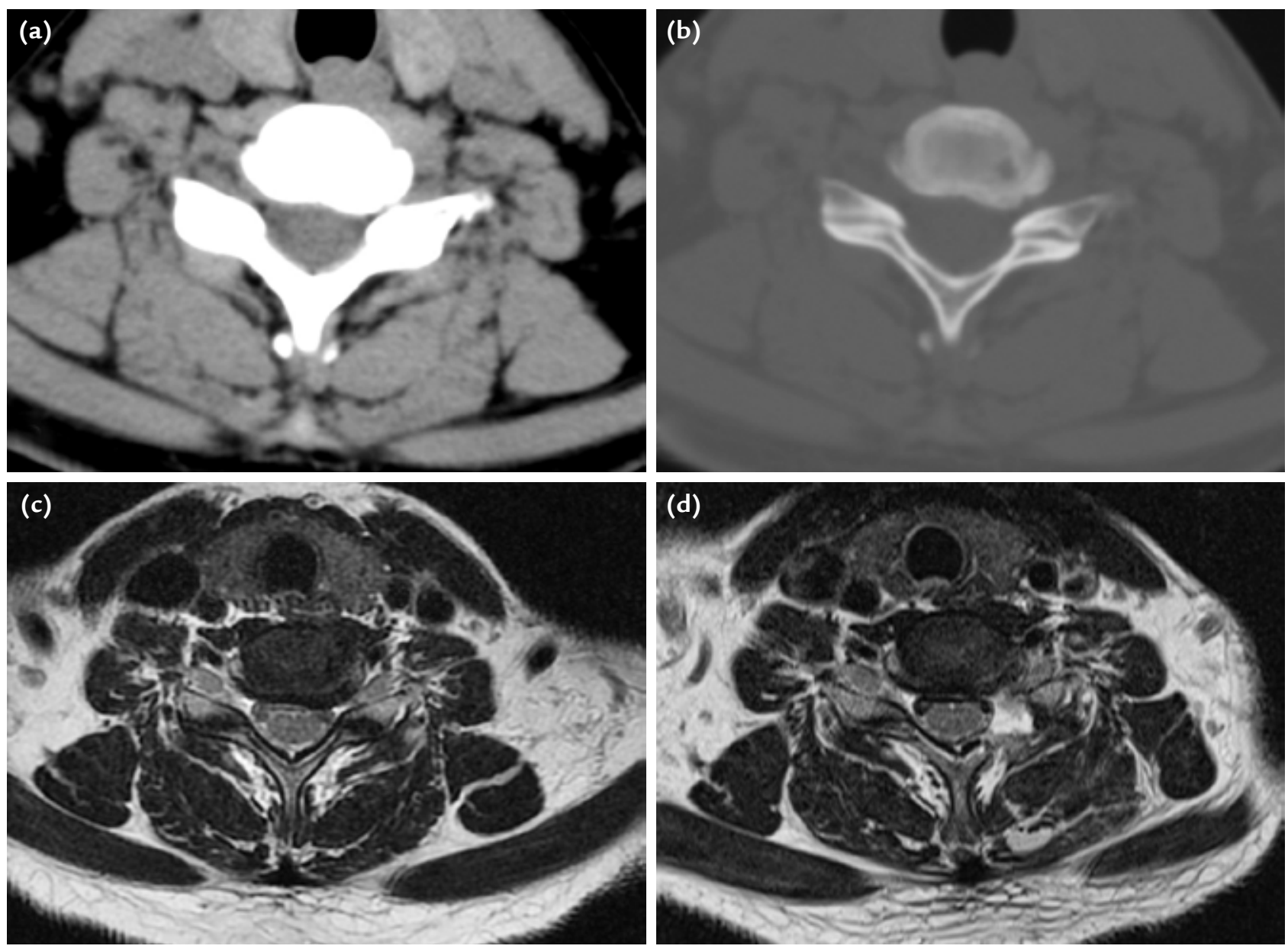

Şekil 6. a-d. Sol C6-C7 foraminal stenozu olan hastanın cerrahi öncesi BT ve MR görüntüleri izlenmekte (a-c). Aynı hastada uygulanan tam endoskopik laminoforaminotomi sonrası, ameliyatın ardından 1. günde çekilen MR görüntüsünde, yapılan foraminal dekompresyon görülmekte (d). Paraspinal kaslarda ve çevre yumuşak dokularda operasyona bağlı travma hemen hemen hiç izlenmemektedir.

Minimal invaziv laminoforaminotomi, güvenli bir teknik olup açık tekniğe göre sonuçları benzerdir. ${ }^{[2,5,7]}$ Minimal invaziv bir girişim olması nedeniyle, operasyonel morbidite azdır (Şekil 6). Ancak, tekniği öğrenme süresinin uzun olması, cerrahi tecrübe gerektirmesi ve endoksopik ekipmanların maliyeti de akılda tutulmalıdır. ${ }^{[2]}$

\section{KAYNAKLAR}

1. Spurling RG, Scoville WB. Lateral rupture of the cervical intervertebral disc: a common cause of shoulder and arm pain. Surg Gynecol Obstet 1944;78:350-8.

2. Siddiqui A, Yonemura K. Posterior Cervical MED and Laminoforaminotomy. In: Kim DH, Fessler RG, Regan JJ, editors. Endoscopic Spine Surgery and Instrumentation: Percutaneous Procedures. New York: Thieme; 2005. p.66-73.
3. Roh SW, Kim DH, Cardoso AC, Fessler RG. Endoscopic foraminotomy using MED system in cadaveric specimens. Spine (Phila Pa 1976) 2000;25(2):260-4.

4. Adamson TE. Posterior cervical endoscopic laminoforaminotomy. In: Shen FH, Samartzis D, Fessler RG, editors. Textbook of the Cervical Spine. Maryland Heights, MO: Elsevier/Saunders; 2015. p.331-6.

5. Fessler RG, Khoo LT. Minimally invasive cervical microendoscopic foraminotomy: an initial clinical experience. Neurosurgery 2002;51(5 Suppl):S37-45.

6. Adamson TE. Microendoscopic posterior cervical laminoforaminotomy for unilateral radiculopathy: results of a new technique in 100 cases. J Neurosurg 2001;95(1 Suppl):51-7.

7. Williams RW. Microcervical foraminotomy. A surgical alternative for intractable radicular pain. Spine (Phila $\mathrm{Pa}$ 1976) 1983;8(7):708-16. 